\title{
Information System Water Quality Testing
}

\author{
Toban T. Pairunan \\ Electrical Engineering Dept \\ Manado State Politecnic \\ North Sulawesi-Indonesia
}

\author{
Yohanis S. Rompon \\ Electrical Engineering Dept \\ Manado State Politecnic \\ North Sulawesi- Indonesia
}

\author{
Nathaniel L. Bijang \\ Electrical Engineering Dept \\ Manado State Politecnic \\ North Sulawesi-Indonesia
}

\begin{abstract}
This research aims to design and build a well water quality testing software and refillable bottled water quality. This testing software is built using data from physical, chemical and microbiological parameter measurement and location of sampling area data. The software is designed using Microsoft Access as the database and Delphi 7 as the programming language. The built-in software is then tested using physical, chemical, and microbiological data of well water and refilled water that has been filtered through the depots of drinking water. Results of samples testing show that application software can be used as a tool to process data of water quality testing and refill drinking water. The software can provide reports on well water quality testing results and refill water according to well areas and water treatment sites. The software can compare parameters that do not meet the quality standard or meet the standard quality in accordance with the SNI standard.
\end{abstract}

\section{General Terms}

Aplication Software, Information System, Water Testing.

\section{Keywords}

Software, Delphi 7, Water Quality Well, Water Refill, Storet Method.

\section{INTRODUCTION}

One of the important human needs is the need for clean water. Clean water is very important because every day we need it for drinking, cooking, bathing, washing and so on. Before being used, water quality must comply with the health standards set by the government. The three commonly used standard are physical, chemical, and biological standard parameters. Measurement of drinking water quality parameters is one of the important requirements for drinking water management before it is used by the community.

Efforts to monitor and control the quality of clean water and drinking water is the activity of measuring and analyzing the quality of well water and also bottled water, required supporting tool devices, both hardware and software.

The problems encountered by researchers in the drinking water quality system at Manado Health Center of North Sulawesi province the lack of water quality inspection software that can be used as application software to manage the water quality data. In some places, researchers encounter information systems that are applied only using word processing software Word processing which serves as a tool to make administrative reports, while the testing of water parameters is done conventionally without involving software. As an effort to control water quality, the Health Office is in need of a software tool to know which areas are polluted or have high concentrations, as well as refillable bottled water companies that pay little attention to the health quality of the devices used or the quality of sanitation. By using this water quality control system, it is expected that this tool software will provide reports on the quality of clean water management at the wells of the community or the quality of drinking water in the bottled water management. Therefore, research on how to build a tool for the management of clean water quality (well) is very important.

\section{LITERATUR REVIEW}

\subsection{Information System}

Information systems can be defined as A system made by humans that consists of components in the organization to achieve a goal, namely presenting information. Information system components can be classified as follows: [5].

A. Hardware and software that serves as a machine

B. People and procedures that are human and machine use.

C. Data is a bridge between human and machine to make a process of data processing.

\subsection{Software Process}

The software process is a series of related activities and results, leading to the generation of software products. These activities could include software development from scratch, although in fact, it is increasingly common that new software is developed by extending and modifying existing systems.

While there are many software processes, there are fundamental activities that are common to all software processes. These activities are: [3].

1. Software specification. The functionality of the software and its operating limits should be defined.

2. Design and implementation of software. Eligible software must be created.

3. Validation of software. The software must be validated to ensure that the software works in accordance with what the customer wants.

4. Software Evaluation. The software should be able to evolve to address changing customer needs.

In the fact that there is no ideal software process, there is plenty of scopes to improve the software process in many organizations. The process could include long-standing techniques, or it could also take advantage of industry best practice software engineering. There are many organizations still rely on special processes and do not use software engineering models in their software development.

\subsection{Software Engineering Model}

In software engineering, many models have been developed to help the software development process. These models generally refer to a system development process model called System Development Life Cycle (SDLC). Model sekuensial linier as shown in Figure 1. In Figure 1. illustrates the linear sequential for software engineering often referred to as the "classic life cycle" or waterfall model. Linear sequential proposes an approach to the development of systematic and sequential software that starts at the level and progress of the system on the overall analysis, design, code, testing, and maintenance.[4]. 


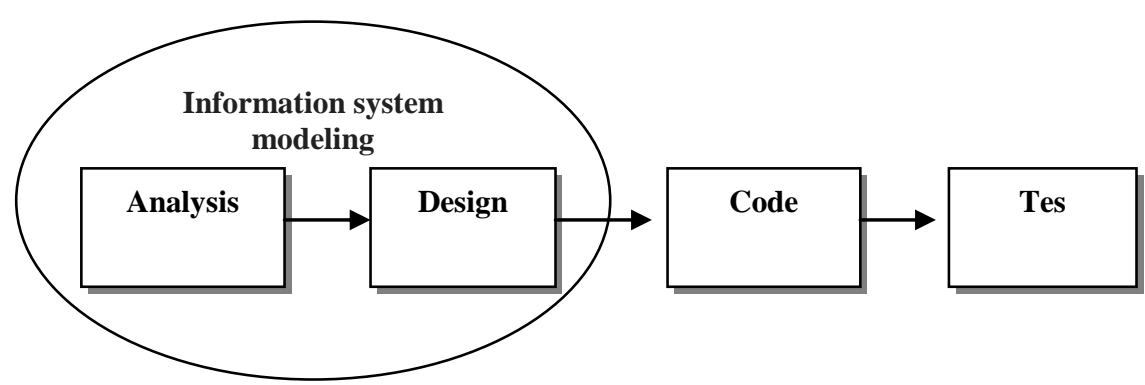

Figure.1. Model Sekuensial linier

Each developed model has its own characteristics.

But in general there are similarities of these models, namely:

$\S$ The need for a clear definition of the problem. The main input of any software development model is the definition of a clear problem. The clearer the better it will be because it will facilitate in solving the problem. Therefore, understanding the problem is an important part of the software development model.

Regular developmental steps.

- Although software development models have different patterns, these models usually follow the general pattern of analysis - design - coding - testing - maintenance.

- Stakeholders play a very important role in the overall development stage. Stakeholders in software engineering can be user owners, developers, programmers, and people involved in the software engineering.

- Documentation is an important part of developing software. Each stage in the model usually produces a number of writings, diagrams, drawings or other forms that should be documented and become an integral part of the resulting software.

- The output of the software development process must be economical. The value of a software is actually a bit hard to the rupee. But the effect of using the software that has been developed must give added value to the organization. This can include reduced operating costs, efficient use of resources, increased organizational benefits, improved "image" of the organization and others

There are many software development models, among others The Waterfall Model, Joint Application Development (JAD), Information Engineering (IE), Rapid Application
Development (RAD), Prototyping, Unified Process (UP), Structural Analysis and Design (SAD), Framework for the

Application of System Thinking (FAST) The Waterfall Model, Prototyping, Unified Process (UP). [4]

\subsection{The waterfall model}

Life cycle model (life cycle model) is the main and basic model of many models. One model that is well known in the world of software engineering is The Waterfall Model. There are 5 main stages in The Waterfall Model as shown in Figure 2 Called Waterfall (means Waterfall) is a process step diagram similar to a storied waterfall. The stages in The Waterfall Model are summarized as follows: [3]

A. The investigation stage is conducted to determine whether there is a problem or there is an opportunity for an information system to be developed. At this stage, feasibility studies need to be done to determine whether the information system to be developed is a viable solution

B. Stage analysis aims to find the needs of users and organizations and analyze existing conditions (prior to the application of new information systems).

C. The design stage aims to determine the detailed specifications of the components of the information system (human, hardware, software, network, and data) and information products in accordance with the results of the analysis phase.

D. Implementation stage is a step to get or develop hardware and software (coding program), do testing, training, and transfer to the new system.

E. Stages of maintenance (maintenance) are done when the information system has been operated. At this stage monitoring process, evaluation and change (improvement) as needed.

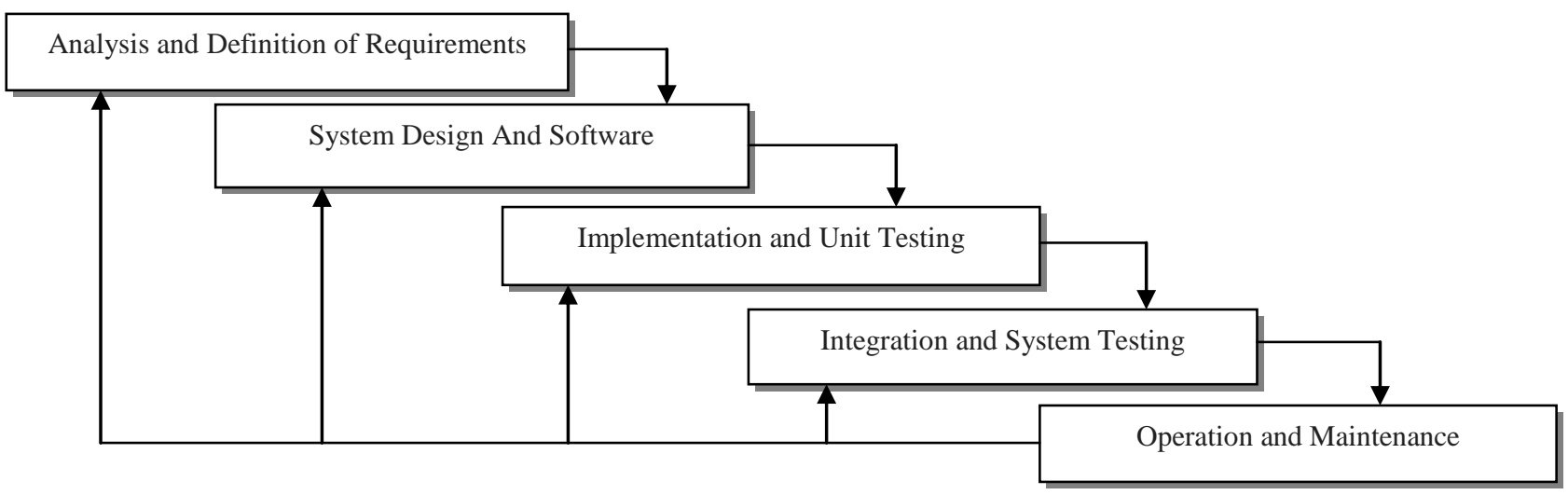

Figure. 2 Software design based on the waterfall model 


\subsection{Calculation Method of Pollution Index (Method of storet)}

\subsubsection{Water Quality Classification}

STORET method is method to determine the status of water quality commonly used. With this storet method, we can know the parameters that have been met or exceeded the water quality standard. In principle, the method of storet is to compare the water quality data with the water quality standard that is adjusted to the allocation to determine the status of water quality.[2].

Table.1 Water Quality Classification

\begin{tabular}{|c|c|c|c|}
\hline CLASS & CHARACTERISTIC & VALUE & STATUS \\
\hline A & Excellent & 0 & Meet the quality standard \\
\hline B & Good & -1 to -10 & Mild pollutants \\
\hline C & Medium & -11 to -30 & Medium pollutants \\
\hline D & Bad & $\geq-31$ & Severe pollutants \\
\hline
\end{tabular}

\subsubsection{Determination of Water Quality Status}

Determination of water quality status by using storet method is done with the following steps:

1. Perform Periodic water quality data collection to form data from time to time (Times series)

2. Compare the measurement data from each water parameter with the value of quality standard in accordance with the water class.
3. If the measurement results meet the water quality standard (Measurement results < quality standard) then given a score of 0

4. If the results of the Measurement do not meet the water quality standard (Measurement Results > quality standard), then given a score like a table 2 as follows: [1].

5. The negative number of all parameters is calculated and determined the quality status of the total score obtained by using the value system.

Table.2. Parameter Scoring Water Quality

\begin{tabular}{|c|c|c|c|c|}
\hline \multirow{2}{*}{$\begin{array}{c}\text { Number of } \\
\text { Sample }\end{array}$} & Value & \multicolumn{3}{|c|}{ Parameters } \\
\cline { 3 - 5 } & & Physics & Chemistry & Biology \\
\hline \multirow{3}{*}{$<10$} & Maximum & -1 & -2 & -3 \\
& Minimum & -1 & -2 & -3 \\
& Average & -3 & -6 & -9 \\
\hline \multirow{3}{*}{$\geq 10$} & Maximum & -2 & -4 & -6 \\
& Minimum & -2 & -4 & -6 \\
& Average & -6 & -12 & -18 \\
\hline
\end{tabular}

\section{RESEARCH METHODS}

\subsection{Design Model}

Software to be built, the information system is illustrated as in the block diagram figure 3 below. In accordance with Figure 3 , the Application consists of a block diagram of the data source, the data source used in this study can be grouped in four parts:

\section{Data of National Standat Indonesia (SNI)}

The data of Indonesian National Standard (SNI) for testing the quality of clean water and drinking water consist of physical, chemical and biological parameters.

\section{Statistical Data}

Administrative data to illustrate the position of the sampling region, consisting of provincial, district, sub-district, village and environmental data.

\section{Measurement Data}

Measurement Data is data obtained from field measurements, whether the measurements are made directly at the measuring point location, or conducted in the testing laboratory. The data included in the measurement data category consists of:

A. Physical Parameter Data (TDS)

B. Biological Parameter Data

C. Chemical parameter data (Concentrations of chemical elements).

\section{Extraction Data}

Extraction data are data obtained from the merging of there kinds of data ie standard data (SNI), statistical data, Measurement data.

Groups of data sources form the database management system. For the model applied in this application is the application of Storet Model, which is used to form a management system whose goal is to calculate the Model for modeling the values of physical quantities according to standard chemistry and biology to produce a status of the parameters measured in a given period. 


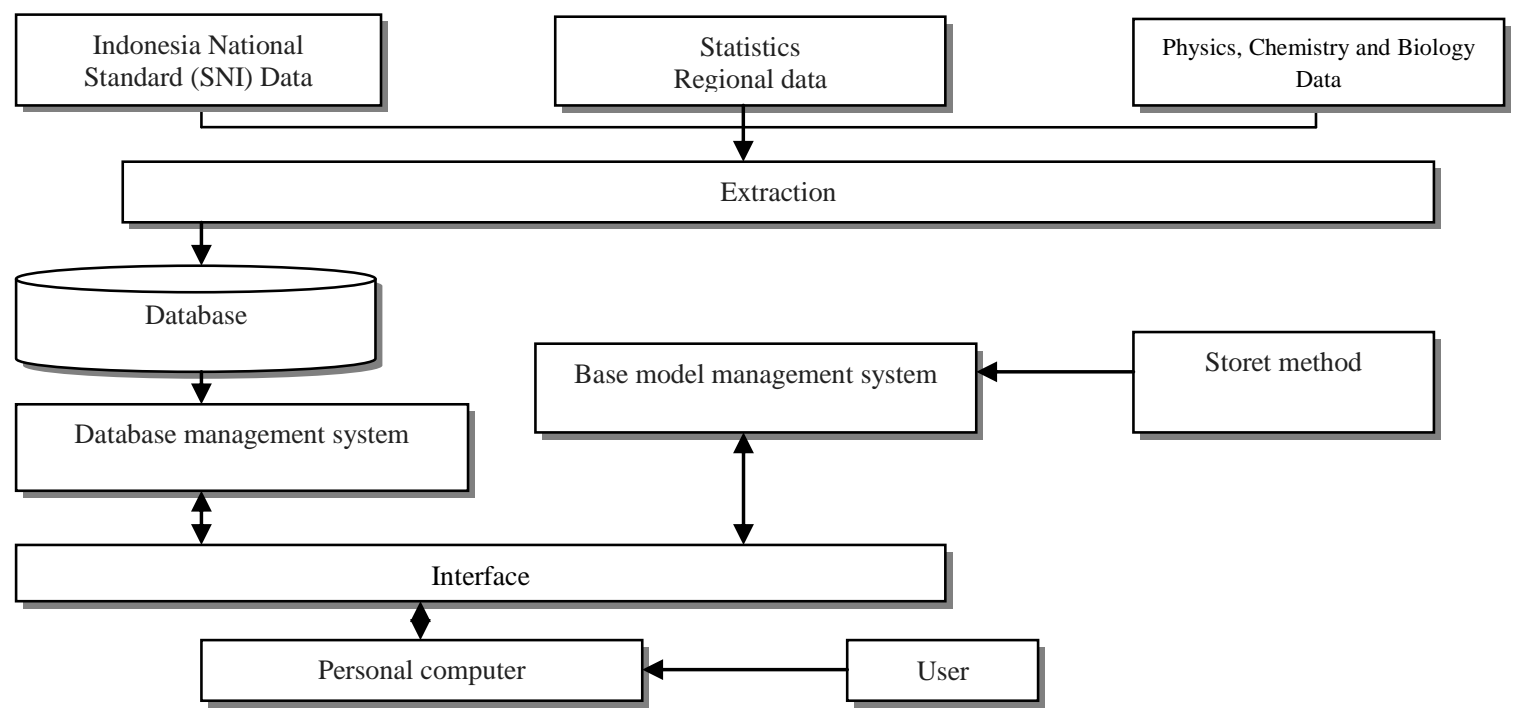

Figure.3 Diagram of Application Information System Water Quality Testing Software

\subsection{Functional Modeling}

Context diagram is a system design that will illustrate how the software system is built. Through a context diagram, illustrated how the relationship between external entities with the application system. Figure 4 below shows the model of the context diagram that will be built.

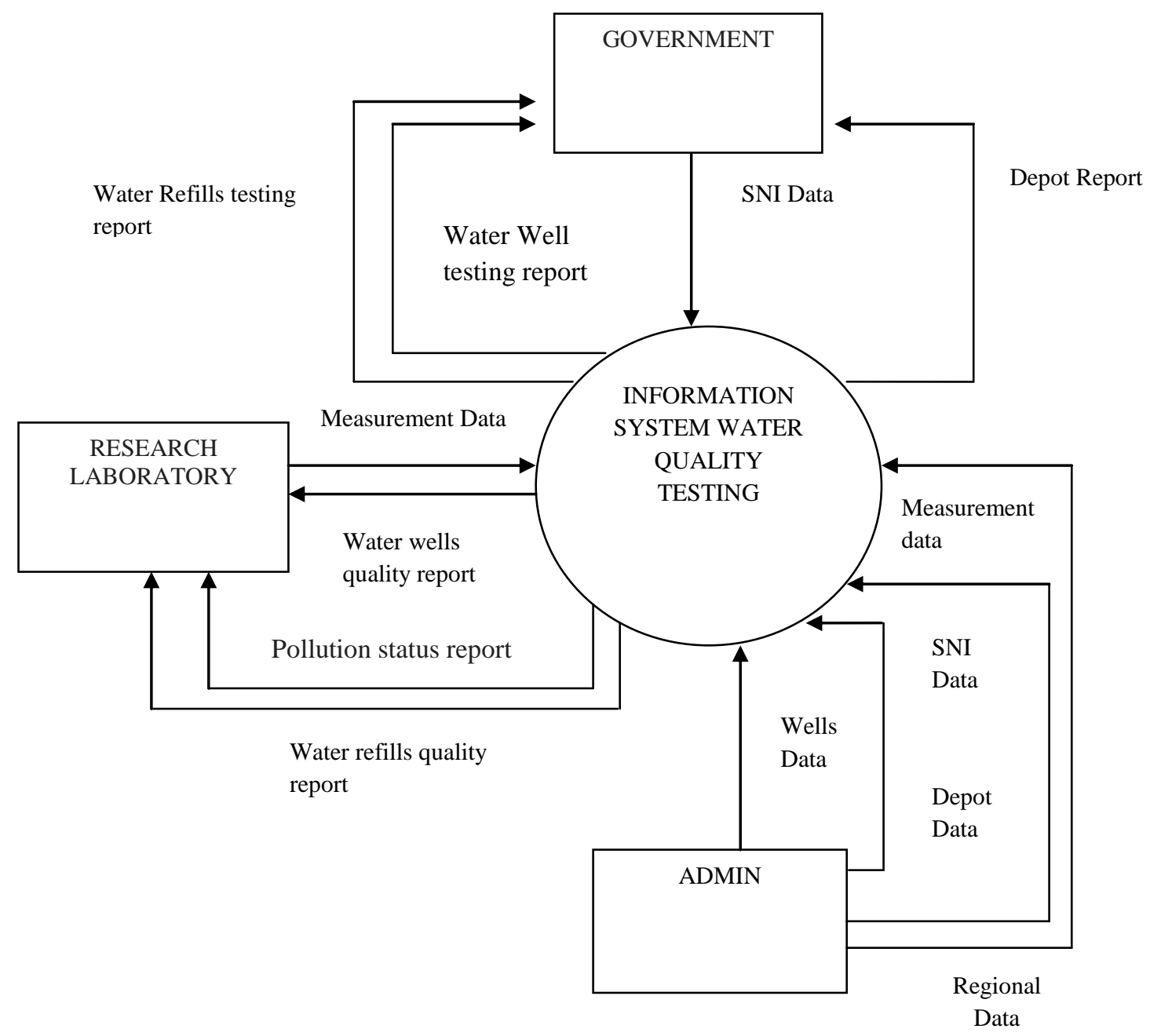

Figure.4 Context Diagram Information System Water Quality Testing 


\section{RESULTS AND DISCUSSION}

After going through the testing process, the application software can run, one of the results looks like Figure5. below.

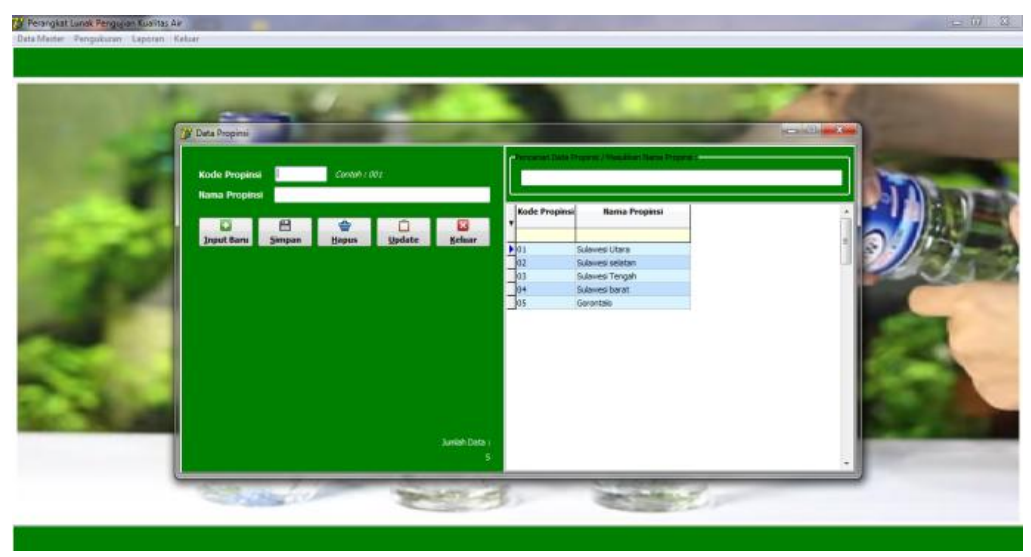

Figure.5. Display interface to input master data

Application system that has passed the testing process, the next step is the implementation of the system. Process Implementation system begins with input master data and measurement results. For the measurement data inputted through the interface as shown in Figure 6 below.

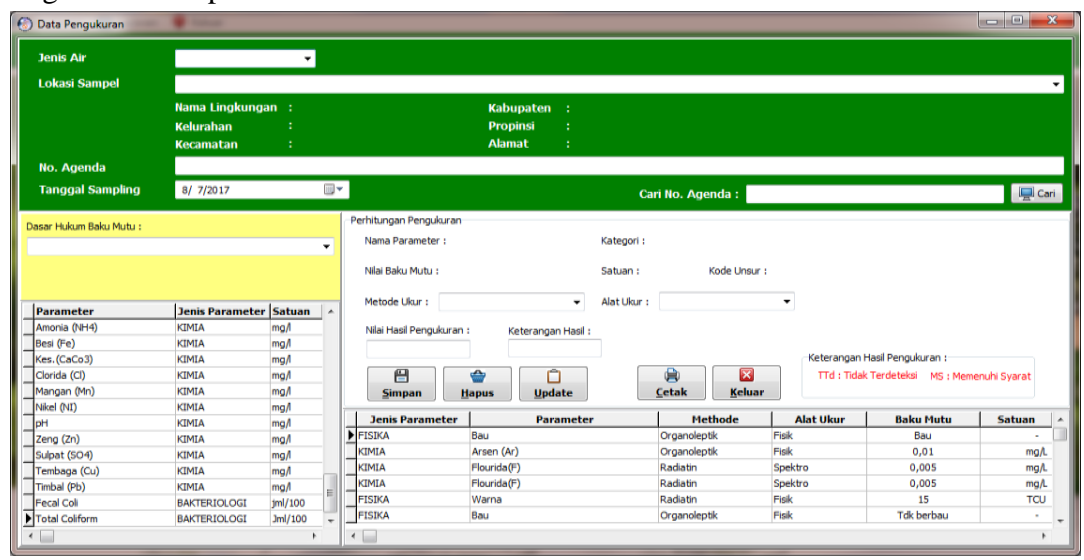

Figure.6. Display Interface to input Measurement Data

The application interface to perform the determination of stored values as shown in the figure 7 . Through the system interface in figure 7 , the system user can determine the quality status of the water being tested, either on well water or water refill. By obtaining a stored value then the status of water quality can be seen through the application.
In practice, the software can be used to determine the status of any water quality, but need to include standard physics, chemistry and microbiology data in accordance with the water quality standards used in the area. Standard data entry of physical, chemical and microbiological parameters is done through standard interface. Due to its limitations, the Researcher does not display in this article.

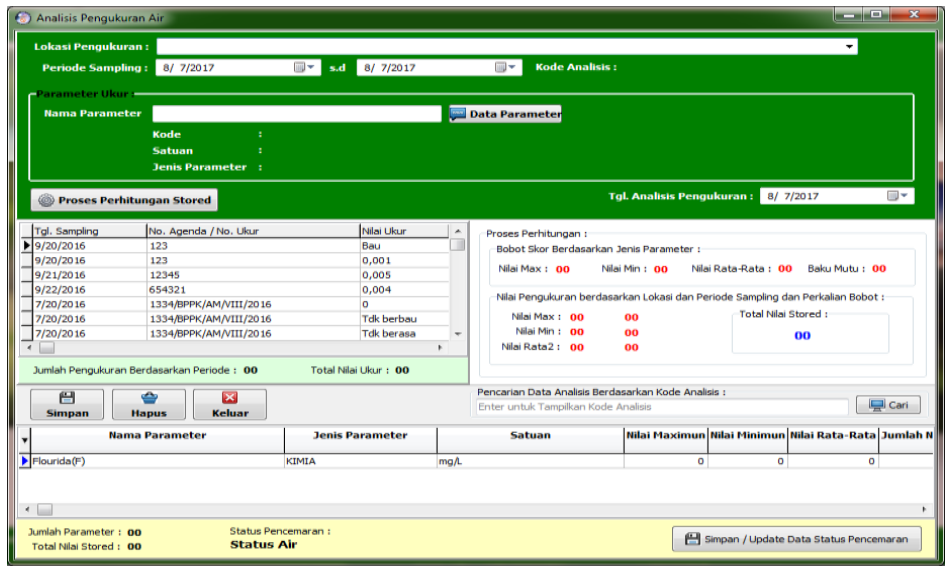

Figure.7 Display interface to see the water quality analysis 


\section{CONCLUSION}

Based on the results of research studies that have been done can be concluded as follows:

Software applications of water quality testing have been successfully made based information system and information technology, As previously planned and successfully tested using field measurement data and laboratory health analysis data.

By following the stages of planning and implementation of this software development, it has been successfully tested using well water testing and drinking water according to user needs.

The software can manage well water quality data and drinking water and produce quality reports from each measurement location. For the development of water quality testing application software can be developed fore using mobile system. Software developers can use other pollution index algorithms to determine the status of water quality.

\section{REFERENCES}

[1] Lampiran Peraturan MENLH Bidang Pembinaan Sarana Teknis dan Peningkatan Kapasitas,2009" Indeks Kualitas Lingkungan Hidup" Kementerian Lingkungan Hidup (KLH).

[2] Pairunan, Toban ,2011," Perangkat lunak pendukung keputusan analysis pengelolaan kualitas dan pengendalian pencemaran air sungai" (Thesis) Program Magister Teknik Elektro Universitas Hasanuddin. pp.1920, 45-47.

[3] Sommerville IAN, 2003, Software Engineering (Rekayasa Perangkat Lunak) edisi 6 jilid 1 Penerbit erlangga PP.40-43.

[4] Pressman Roger S ,1997 Rekayasa Perangkat Lunak Pendekatan Praktisi (buku satu) Mc Graw Hill Book Co. diterjemahkan oleh Penerbit Andi Offset.pp 35-42.

[5] Jamaluddin Alba ,2012 Analisa desain system informasi, Graha Ilmu. 